Portland State University

PDXScholar

\title{
A Case Study of Drone Delivery Reliability for Time- Sensitive Medical Supplies with Stochastic Demand and Meteorological Conditions
}

Travis B. Glick

Portland State University, tglick@pdx.edu

Miguel Figliozzi

Portland State University, figliozzi@pdx.edu

Avinash Unnikrishnan

Portland State University, uavinash@pdx.edu

Follow this and additional works at: https://pdxscholar.library.pdx.edu/cengin_fac

Part of the Transportation Engineering Commons

Let us know how access to this document benefits you.

\section{Citation Details}

Glick, Travis B.; Figliozzi, Miguel; and Unnikrishnan, Avinash, "A Case Study of Drone Delivery Reliability for Time-Sensitive Medical Supplies with Stochastic Demand and Meteorological Conditions" (2020). Civil and Environmental Engineering Faculty Publications and Presentations. 573.

https://pdxscholar.library.pdx.edu/cengin_fac/573

This Pre-Print is brought to you for free and open access. It has been accepted for inclusion in Civil and Environmental Engineering Faculty Publications and Presentations by an authorized administrator of PDXScholar. Please contact us if we can make this document more accessible: pdxscholar@pdx.edu. 


\title{
A CASE STUDY OF DRONE DELIVERY RELIABILITY FOR TIME-SENSITIVE MEDICAL SUPPLIES WITH STOCHASTIC DEMAND AND METEOROLOGICAL CONDITIONS
}

\author{
Travis B. Glick \\ Transportation Technology and People (TTP) Lab \\ Department of Civil and Environmental Engineering \\ Portland State University \\ PO Box 751 — CEE, Portland, OR 97207-0751 \\ Fax: 503-725-5950; Email: tglick@pdx.edu \\ Miguel A. Figliozzi (Corresponding Author) \\ Co-Director, TTP Lab \\ Professor, Department of Civil and Environmental Engineering \\ Portland State University \\ PO Box 751 — CEE, Portland, OR 97207-0751 \\ Phone: 503-725-4282; Fax: 503-725-5950; Email: figliozzi@pdx.edu \\ Avinash Unnikrishnan \\ Co-Director, TTP Lab \\ Associate Professor, Department of Civil and Environmental Engineering \\ Portland State University \\ PO Box 751 - CEE, Portland, OR 97207-0751 \\ Phone: 503-725-2872; Fax: 503-725-5950; Email: uavinash@pdx.edu
}

Word count: $6748+3$ tables $\times 250$ words $($ each $)=7448$ words

Manuscript Number: TRBAM-21-02798

Original Submission: 31 July 2020

Revision Submission: 28 November 2020

Paper accepted for presentation at the 2021 TRB Annual Meeting (January 2021, Washington DC) and potential publication in Transportation Research Record. 


\section{ABSTRACT}

Drones are increasingly being utilized to deliver medical supplies, and the COVID-19 pandemic has accelerated this trend. Drones arrive quickly by taking more direct paths and avoiding ground-based obstructions. However, drones are not completely reliable and may also experience failures and delays. For consumer products, delivery delays are an inconvenience, but for some medical supplies, delays may be fatal. This research focuses on the drone reliability of one particular type of supply and event: automatic defibrillators for out-of-hospital cardiac arrests (OHCA). A modeling framework is developed to analyze drone delivery reliability with stochastic demands and meteorological conditions. Using probability distributions based on real data from Portland, OR, this research quantifies the failure rates as a function of drone range and meteorological conditions that include temperature, precipitation, and wind. Tradeoffs among drone reliability, fleet size, population size, and meteorological conditions are analyzed.
\end{abstract}

Keywords: Drone Deliveries, Reliability, Stochastic Modeling, Time-sensitive, Case Study, Defibrillators 


\section{INTRODUCTION AND MOTIVATION}

Drone deliveries are being tested across the globe to meet not only parcel delivery demands but also to open new service models and opportunities where traditional ground delivery methods are relatively slow and unreliable. The delivery of medical supplies is an area that has sparked high interest because such supplies are often subject to strict temporal constraints. For example, drones have already been employed for the delivery of medical supplies in Rwanda, a country that experiences heavy rains that often lead to road impassibility [1]. Hospital supply chains in Rwanda now utilize drones for the delivery of blood from central storage facilities [2] [3]. While blood deliveries are time-sensitive, some medical supplies are subject to even more stringent time considerations.

The COVID-19 and the consequent lockdown have temporality remove some regulatory barriers for the deployment of drones. Drones are now being tested in several states such as Florida, North Carolina, North Dakota and Virginia to deliver prescriptions, and there is a promising trial in Baltimore to deliver kidneys for transplants [4]. Even though there is a wide range of drone applications in the health sector, this research and case study focuses on time-sensitive cardiac arrests.

Cardiac defibrillation [5] needs to be administered minutes after diagnosis to avoid patient death, but a majority $(63 \%)$ of cardiac arrest cases occur outside of hospitals where defibrillators are not readily available. The survival rate for out-of-hospital cardiac arrest (OHCA) in 2016 was 12\%, almost half that of the in-hospital rate (25\%) [6]. Currently, automatic external defibrillators (AED) are $1.1 \mathrm{~kg}(2.4 \mathrm{lb})$, take just $1.77 \mathrm{~L}$ (108 in 3$)$ of space, and come with instructions to guide non-medical persons through the machine's use [7]. This makes AEDs an ideal candidate for drone delivery. However, the seriousness of cardiac arrest puts tight constraints on adequate arrival times. Even in hospitals, defibrillation survival rates after 3 minutes are reduced from $39 \%$ to $22 \%$, and each additional minute reduces the chance of survival by approximately 4\% [8]. Currently, the average ground-based (ambulance) emergency response time in the United States is much longer than three minutes, with a mean of 7.0, 7.7, and 14.5 minutes for urban, suburban, and rural areas, respectively [9]. As drones are not subject to the typical ground road infrastructure restrictions, they may have a higher probability of timely response.

Pilots for medical supply deliveries using drones have begun in the United States [10], and recent research into drone deliveries of AEDs has attempted to quantify delivery times, estimate mortality rates, and optimize delivery networks through theoretical models [11] [12] [13]. These studies have provided useful tools for AED delivery but have ignored key factors, such as weather. Such exclusions and the lack of real-world data means the viability of drone deliveries for time-sensitive supplies remains an open question.

This research focuses on drone deliveries of AEDs for OHCA and fills a gap in recent research by using real-world data to model and assess the impact of weather on drone delivery reliability and to quantify the impact of fleet size and population on failure rates. Determining the number of drones required to service an area is a difficult challenge as the rate of cardiac events for an area is dependent on population size and time of day [5].

This research: first, models demand and estimates failure rates as a function of drone fleet size and population for two types of drone operations: battery recharging and battery swapping; second, model temperature, precipitation, and wind using historical data from Portland, OR; and third, quantifies the impact of temperature, precipitation, and wind on the range and drone delivery failure. Conclusions, based on results, are discussed with recommendations for future studies.

\section{MODELING DEMAND, FLEET SIZE, AND FAILURE RATE}

The American Heart Association (AHA) provides a population mean $\left(\mu_{N}\right)$ and confidence intervals (CI) for the number of OHCA events in a year [6]. From the CI, a population variance $\left(\sigma_{N}^{2}\right)$ may be calculated. $\mu_{N}$ and $\sigma_{N}^{2}$ are for the US population as a whole $(N)$, not for a selected sample of $n$ people. For a sample population over a year, the mean and standard deviation for the number of OHCA may be calculated as: 


$$
\begin{array}{ll}
\mu_{N}=356,461 & \sigma_{N}=3,067 \\
\mu_{n}=\left(\frac{n}{N}\right) \mu_{N} & \sigma_{n}=\sqrt{\left(\frac{n}{N}\right) \sigma_{N}^{2}}
\end{array}
$$

Modeling the number of occurrences in a given time interval is a common application of the Poisson distribution with parameter $\lambda_{n}$. To capture the variation of $\lambda_{n}$ for a given population, $\lambda_{n}$ is also simulated using a Gamma distribution with shape and rate parameters $\alpha$ and $\beta$, respectively. In Bayesian statistics, the Gamma distribution is the conjugate prior for Poisson, and equations for the mean and variance may be defined as follows [14].

$$
E\left[\lambda_{n}\right]=\mu_{n}=\frac{\alpha}{\beta} \quad \operatorname{Var}\left[\lambda_{n}\right]=\sigma_{n}^{2}=\frac{\alpha}{\beta^{2}}
$$

Solving for $\alpha$ and $\beta$, the parameters of the gamma distribution for $\lambda_{n}$ are:

$$
\alpha=\frac{\mu_{n}^{2}}{\sigma_{n}^{2}}=\frac{\left(\left(\frac{n}{N}\right) \mu_{N}\right)^{2}}{\left(\frac{n}{N}\right) \sigma_{N}^{2}}=\left(\frac{n}{N}\right) \frac{\mu_{N}^{2}}{\sigma_{N}^{2}} \quad \beta=\frac{\mu_{n}}{\sigma_{n}^{2}}=\frac{\left(\frac{n}{N}\right) \mu_{N}}{\left(\frac{n}{N}\right) \sigma_{N}^{2}}=\frac{\mu_{N}}{\sigma_{N}^{2}}
$$

For any population, $n$, the number of cardiac events in a year may be simulated using:

$$
\lambda_{n} \sim \operatorname{Gamma}\left(\alpha=\left(\frac{n}{N}\right) \frac{\mu_{N}^{2}}{\sigma_{N}^{2}}, \beta=\frac{\mu_{N}}{\sigma_{N}^{2}}\right)
$$

Given this formulation, random OHCA events are simulated using a Poisson distribution with rate parameter, $\lambda_{n}$, defined by AHA data. The above provides estimates for a full year. However, the number of OHCA is also temporally dependent.

There is no statistically significant variation across months or seasons, but day-of-week and timeof-day do have significant variation. Incidence rate ratios (IRR) with $95 \%$ confidence intervals are used for simulation, where the highest increases are seen on Mondays [1.18, 1.38] and during the 8:00 AM to 9:00 AM hour [1.96, 2.59] [15]. Combined, Monday mornings have an average rate increase of 2.91 over the yearly average OHCA rate. Normal distributions are assumed for each IRR, based on the Central Limit Theorem of probability [14], and the time between consecutive OHCA events may be simulated utilizing a Poisson process of rate $\lambda_{n}$. Figure 1 shows the asymmetry of the distribution around the mean for the time between events as a function of population size.
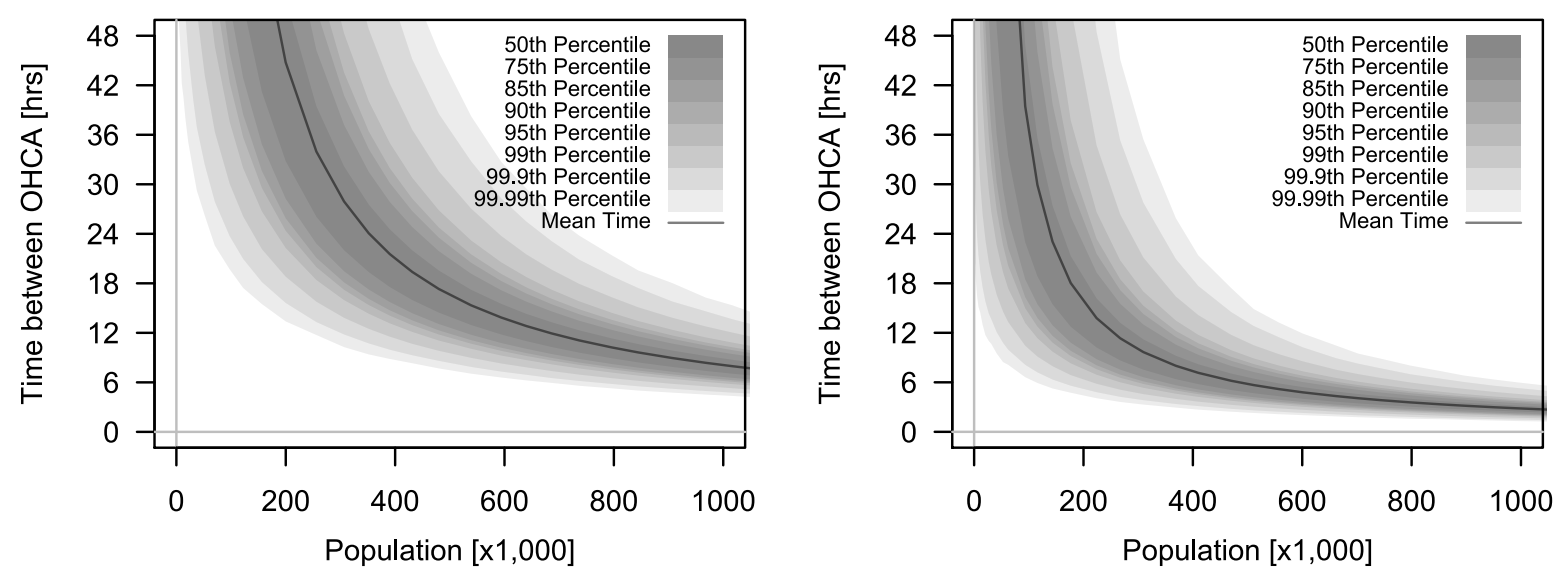

Figure 1 Time between consecutive OHCA events versus population for US average demand rate (left) and rate on Monday between 8:00 AM and 9:00 AM (right) 


\section{Fleet Size, Drone Repositioning, and Battery Swapping Times}

The number of required drones is based on the shortest time between events, given the nearly threetimes increase over the average rates for Monday mornings, but also on the time it takes to serve a patient and reposition a drone. The calculated number of drones is, therefore the minimum required during peak demand and above the minimum for all other days-of-the-week and times-of-day. Two options are considered: in-drone battery recharging and battery swapping. For this study, we assume that a highperformance multi-copter MD4-3000 drone is utilized. Drone specifications are given in Table 1 [16].

The optimal range is assumed to be $50 \mathrm{~km}(31 \mathrm{mi})$, which assumes ideal weather conditions and a cruise speed of $20 \mathrm{~m} / \mathrm{s}(44.7 \mathrm{mph})$. With a $1.1 \mathrm{~kg}(2.4 \mathrm{lb})$ payload, the flight time will be approximately 42 minutes. The battery capacity of drones used in this study has a 21,000mAh [17]. The LiPo battery has a recommended recharge rate of $2 \mathrm{~A}$ at greater than $90 \%$ charge efficiency [18]. Therefore, the charge time following a complete drain of the battery for one of these drones is between 10 hours 30 minutes and 11 hours 40 minutes. However, batteries will not experience a full drain each time they are used, and there will be additional variability in the charge times based on distance traveled.

Table 1 MD4-3000 drone characteristics

\begin{tabular}{|l|l|}
\hline Specification & MD4-3000 \\
\hline Take off / Gross weight $m$ & $11.1 \mathrm{~kg}(24.5 \mathrm{lb})$ \\
Tare $/$ Curb Weight $m_{t}$ & $10.0 \mathrm{~kg}(22.1 \mathrm{lb})$ \\
Payload $m_{l}$ & $1.1 \mathrm{~kg}(2.4 \mathrm{lb})$ \\
Empty weight factor $c_{m}$ & 0.90 \\
Battery/Fuel Storage Capacity* & $777 \mathrm{wh}$ \\
Loaded Flight Time $\left(m_{l}=1.1 \mathrm{~kg}\right)$ & $42 \mathrm{minutes}$ \\
Range $\left(m_{l}=1.1 \mathrm{~kg}\right)$ & $50 \mathrm{~km}(31 \mathrm{mi})$ \\
\hline
\end{tabular}

Given the random distribution of OHCA events and the combination of service and charge time of batteries, $\mathrm{M} / \mathrm{M} / \mathrm{c}$ queuing theory may be employed to determine the number of needed drones. For service times, it is assumed that a drone must stay with a patient until paramedics arrive (an average of 8 minutes) [9], stabilize the patient (averaging 2 minutes), have the automatic defibrillator repackaged for the return trip (averaging 5 minutes), and return to base (averaging 5 minutes of flight and landing time). In addition to these 20 minutes of service times, drones are additionally unavailable to service new patients while their batteries are recharged (case 1) or swapped for a fully charged battery (case 2).

In case 1 , given an average of 10 minutes of active flight time to and from a patient and the available flight time of 42 minutes, the average recharge time will be about 2 hours 40 minutes. Adding the 20 minutes of service time, the average usage time is 3 hours, which corresponds to an average of 8 possible services per day. Using an $\mathrm{M} / \mathrm{M} / \mathrm{c}$ queueing model, failure was defined as the probability that there will be one or more people in the queue (i.e., a person is waiting to be served due to drone unavailability). The rate of OHCA $\left(\lambda_{n}\right)$ used is the worst-case scenario (i.e., 8:00 AM - 9:00 AM on Mondays). Figure 2 shows failure probability (plotted logarithmically) for case 1, as a function of population and the number of available drones.

In case 2, after 20 minutes of average service time, each drone is assumed unavailable for an additional 10 minutes ( 30 minutes total) to allow for the battery to be swapped with a fully charged battery. Figure 3 gives failure probabilities for case 2 given $\mathrm{M} / \mathrm{M} / \mathrm{c}$ queuing theory using the Monday morning rate. By swapping batteries, the number of possible services per day increases by a factor of 6 , from 8 (in case 1 , battery recharging) to 48 (in case 2 , battery swapping). 


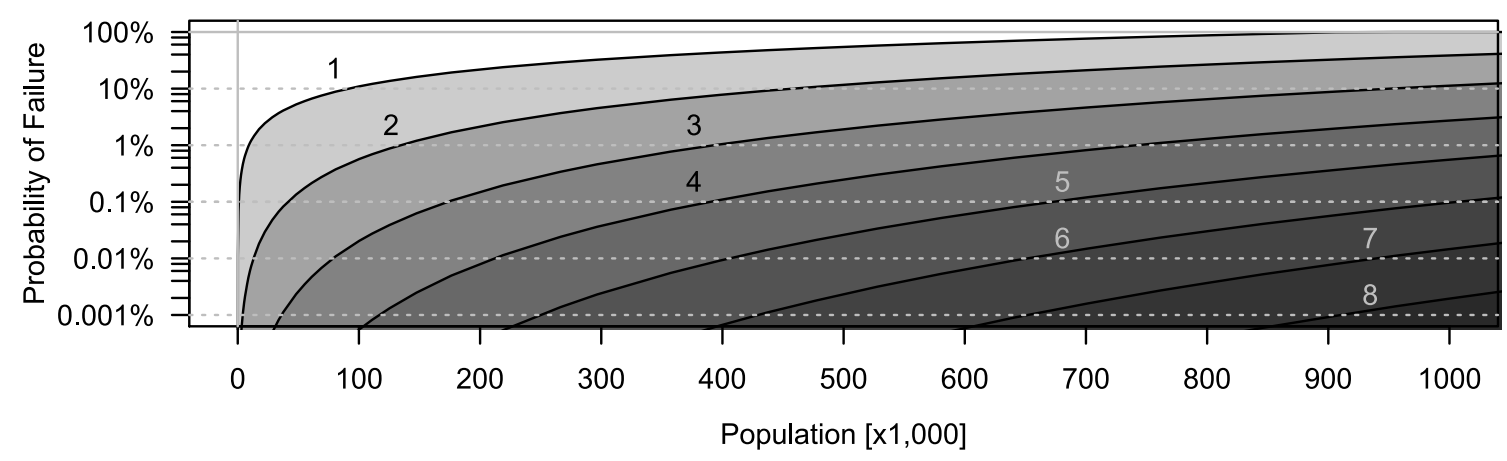

Figure 2 Case 1 (Battery Recharging): Probability of failure versus population and number of drones given the demand rate on Mondays between 8:00 AM - 9:00 AM

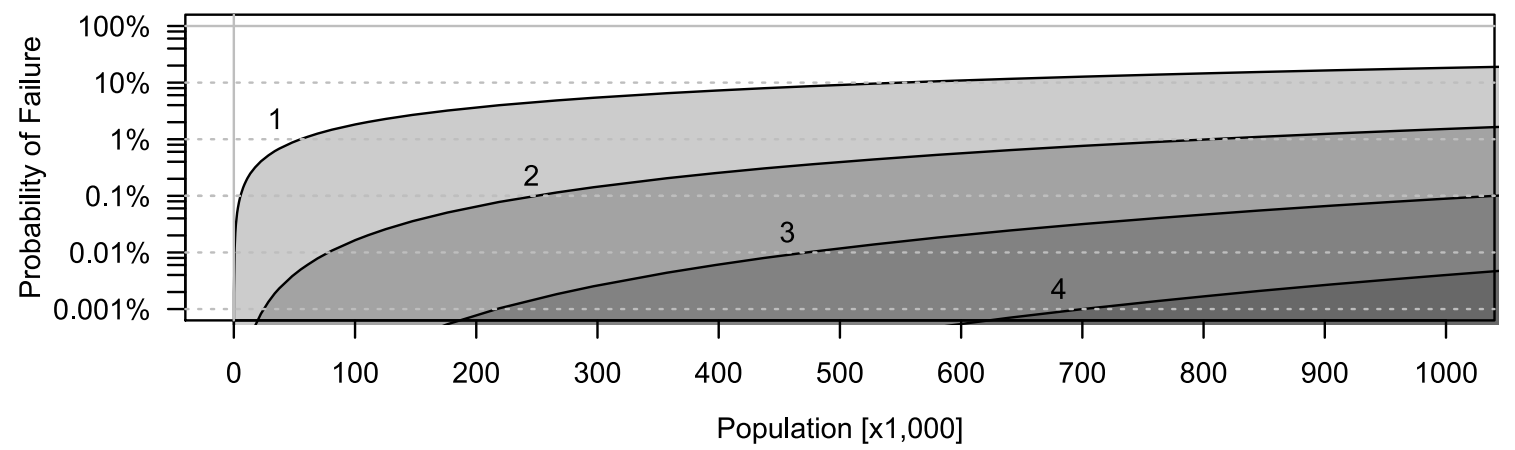

Figure 3 Case 2 (Battery Swapping): Probability of failure versus population and number of drones given the demand rate on Mondays between 8:00 AM - 9:00 AM

For 100,000 people on Monday mornings, a single drone would fail to provide service $10.9 \%$ of the time in case 1 versus just $1.8 \%$ of the time in case 2 . Picking an acceptable failure rate for vital medical supplies of $<0.1 \%$, three drones are required in case 1 , and two drones are required in case 2 . For 300,000 people and a $<0.01 \%$ failure rate, five and three drones are case 1 and 2 , respectively. This difference corresponds to notable cost savings; each drone can cost between $\$ 50,000-\$ 100,000$ [19], but batteries cost between $\$ 300-\$ 600$ [18]. For 300,000 people and a failure rate of $<0.01 \%$, consider a theoretical requirement of one extra drone in both cases; and one or ten spare batteries per drone in cases 1 and 2, respectively. Equipment costs are $30 \%$ less in case 2 than in case 1 . Lastly, other extreme conditions, such as those caused by wildfires, are also a potential issue, but outside the scope of the paper given the lack of detailed long-term wildfire data, the unique complexity of this topic, and the unusual set of operating constraints. A further potential issue is maintenance time and mechanical reliability of drones, but this topic is also outside of the scope of the paper due to the lack of drone reliability data.

\section{WEATHER MODELING}

\section{Modeling Temperature Data and Distributions}

Historical temperature data for a region typically gives a mean, high, and low temperature for each daily record. Figure 4 shows a histogram of January and July daily high temperatures from historical tables from Portland, OR. Given the shape of the temperature histograms, each month's high and low temperatures are assumed to follow a normal distribution. Therefore, historical data provides the ability to calculate means for high and low temperatures and their respective standard deviations for simulation. However, on a given day, high and low temperatures are highly correlated, and this must be considered for simulations. 


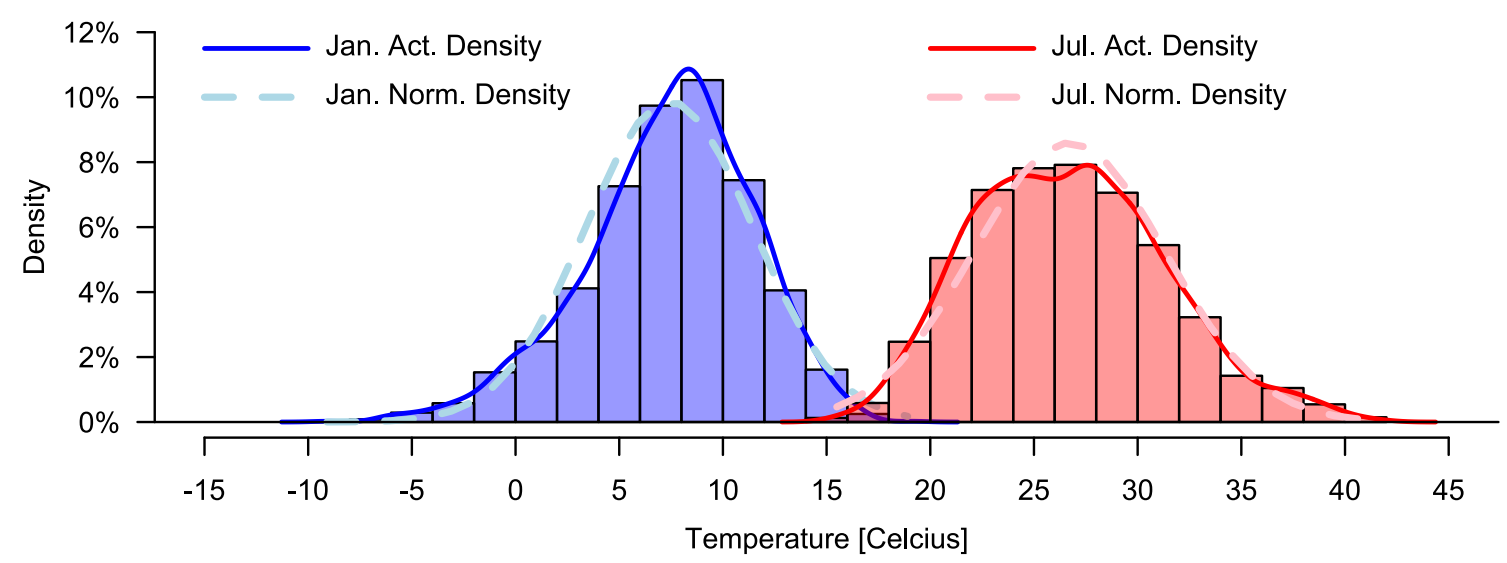

Figure 4 Histogram, density, and normal approximation of historical high temperatures for January and July

To generate a pair of correlated random normal variables, $y_{1}$ and $y_{2}$, with known means, $\mu_{1}$ and $\mu_{2}$, variances, $\sigma_{1}^{2}$ and $\sigma_{2}^{2}$, and correlation, $\rho$, the following may be used [20]:

$$
\begin{array}{ll}
x_{1}=\mathcal{N}(0,1) & y_{1}=\mu_{1}+x_{1} \sigma_{1} \\
x_{2}=\mathcal{N}(0,1) & y_{2}=\mu_{2}+\sigma_{2}\left(x_{1} \rho+x_{2} \sqrt{1-\rho^{2}}\right)
\end{array}
$$

$y_{1}$ and $y_{2}$ are the simulated low and high temperatures for a given day and will have the desired means, variances, and correlations. However, it is still possible for the high and low temperature to be reversed (i.e. $y_{1}>y_{2}$ ). Simply swapping the values, such that all smaller values of the pair are in one list and larger values are in the other, will increase the correlation. Through simulation, this increase in correlation can be measured, and the ratio of the simulated correlation $\left(\rho_{s}\right)$ and actual correlation $(\rho)$ maybe used to correct for the artificial increase.

$$
\rho^{\prime}=\frac{\rho}{\left(\frac{\rho_{s}}{\rho}\right)}=\rho\left(\frac{\rho}{\rho_{s}}\right)=\frac{\rho^{2}}{\rho_{s}}
$$

Using $\rho^{\prime}$ in place of $\rho$ and swapping paired values, as described above, results in a paired list of high and low temperatures with correlation $\rho$. Monthly trends from Portland's historical data are shown in Table 2, with both the observed correlation from the data $(\rho)$ and corrected correlation $\left(\rho^{\prime}\right)$ used for simulation. Unfortunately, these calculated means would be low if used for future predictions. Within the data set used in this analysis, there is a statistically significant positive slope for average high and average low temperatures of 0.01591 and 0.0228 , respectively. For standard deviations, the slopes are statistically insignificant. Equations for the increase in mean highs and lows, compared to the aggregated historical averages, are given below, where $y$ is the current year.

$$
\Delta_{t_{l o}}=0.0228 y-45.1480
$$$$
\Delta_{t_{h i}}=0.0159 y-31.4535
$$ 
Table 2 Historical monthly high and low temperatures $\left({ }^{\circ} \mathrm{C}\right)$ and correlation factors

\begin{tabular}{|l|r|r|r|r|r|r|}
\hline \multirow{2}{*}{ Month } & \multicolumn{2}{|c|}{ High Temperature } & \multicolumn{2}{c|}{ Low Temperature } & \multicolumn{2}{c|}{ Correlation } \\
\cline { 2 - 7 } & \multicolumn{1}{|c|}{ Mean } & Std. Dev. & \multicolumn{1}{c|}{ Mean } & Std. Dev. & Observed & Corrected \\
\hline January & 7.41 & 4.04 & 1.19 & 4.12 & 0.788 & 0.782 \\
February & 10.34 & 3.61 & 2.31 & 3.52 & 0.534 & 0.523 \\
March & 13.08 & 3.76 & 3.70 & 2.98 & 0.243 & 0.225 \\
April & 16.09 & 4.36 & 5.64 & 2.77 & 0.285 & 0.271 \\
May & 19.80 & 4.99 & 8.76 & 2.70 & 0.390 & 0.377 \\
June & 22.82 & 4.82 & 11.68 & 2.31 & 0.418 & 0.409 \\
July & 26.70 & 4.64 & 13.84 & 2.11 & 0.422 & 0.420 \\
August & 26.69 & 4.53 & 13.95 & 2.21 & 0.286 & 0.282 \\
September & 23.92 & 4.79 & 11.26 & 2.82 & 0.169 & 0.158 \\
October & 17.61 & 4.10 & 7.59 & 3.23 & 0.286 & 0.269 \\
November & 11.40 & 3.50 & 4.25 & 3.84 & 0.639 & 0.629 \\
December & 7.80 & 3.65 & 1.90 & 3.77 & 0.775 & 0.769 \\
\hline
\end{tabular}

The probabilities that the average daily and 8:00 AM temperatures are less than $0^{\circ} \mathrm{C}$ is important to the calculations of precipitation; as such, the increases are also important for future predictions. For any normally distributed variable, $X$, multiplied by a constant, $c$, the resulting distribution $c X$ is also normal with mean, $c \mu$, and variance, $c^{2} \sigma^{2}[21]$.

$$
X \sim \mathcal{N}\left(\mu, \sigma^{2}\right) \quad c X \sim \mathcal{N}\left(c \mu, c^{2} \sigma^{2}\right)
$$

In addition, the sum of any two normally distributed variables, $X$ and $Y$, with means, $\mu_{1}$ and $\mu_{2}$, variances, $\sigma_{1}^{2}$ and $\sigma_{2}^{2}$, and correlation, $\rho$, will also be normal [22].

$$
X+Y \sim \mathcal{N}\left(\mu_{1}+\mu_{2}, \sigma_{1}^{2}+\sigma_{2}^{2}+2 \rho \sigma_{1} \sigma_{2}\right)
$$

For average daily temperature, the distribution of average temperature may be found by averaging the distributions of high and low temperatures. Given means, $\mu_{1}$ and $\mu_{2}$, variances, $\sigma_{1}^{2}$ and $\sigma_{2}^{2}$, and correlation, $\rho$, the distribution of the average daily temperature will be:

$$
\mathcal{N}\left(\frac{\mu_{1}}{2}+\frac{\mu_{2}}{2}, \frac{\sigma_{1}^{2}}{2^{2}}+\frac{\sigma_{2}^{2}}{2^{2}}+2 \rho\left(\frac{\sigma_{1}}{2}\right)\left(\frac{\sigma_{2}}{2}\right)\right)=\mathcal{N}\left(\frac{\mu_{1}+\mu_{2}}{2}, \frac{\sigma_{1}^{2}+\sigma_{2}^{2}}{2^{2}}+\frac{\rho \sigma_{1} \sigma_{2}}{2}\right)
$$

The probability that the average daily temperature is less than $0^{\circ} \mathrm{C}$ may be directly calculated for this normal distribution. This section presents the general statistical framework to analyze temperatures. In the specific application and case study, at 8:00 AM (worst case scenario), the probability is based only on the distribution of low temperatures.

\section{Modeling Precipitation (Rain and Snow) Data and Distributions}

Many regions have systems to measure rainfall. Often, the amount of rain per day and the amount of snow per day are included. For precipitation generally in the US, 13 inches $(33 \mathrm{~cm})$ of snow equals one inch of precipitation. This conversion allows for total precipitation per day to be calculated. The same data weather data set for Portland, OR, provided historical rain and snow measurements, which were combined. Table 3 shows the estimates for the mean and variance of precipitation on days with rainfall, and the calculated percent of days without rainfall for each month. 
Table 3 Probability of zero rain on a given day, and daily means and variances of precipitation for each month.

\begin{tabular}{|l|r|r|r|}
\cline { 3 - 4 } \multicolumn{1}{c|}{} & Probability of & \multicolumn{2}{c|}{$\begin{array}{c}\text { Daily Precip. Rate } \\
\text { Zero Precip. on } \\
\text { MRate }>\text { 0 mm] }\end{array}$} \\
\cline { 3 - 4 } Month & Given Day & Mean & Variance \\
\hline January & $32.6 \%$ & 7.7 & 77.1 \\
February & $36.6 \%$ & 6.4 & 59.2 \\
March & $35.3 \%$ & 5.6 & 35.5 \\
April & $42.0 \%$ & 4.2 & 21.7 \\
May & $54.0 \%$ & 4.7 & 30.1 \\
June & $64.6 \%$ & 4.4 & 28.8 \\
July & $86.6 \%$ & 3.7 & 22.8 \\
August & $83.8 \%$ & 4.6 & 34.7 \\
September & $72.8 \%$ & 5.6 & 55.9 \\
October & $52.7 \%$ & 6.5 & 61.6 \\
November & $32.7 \%$ & 7.7 & 83.2 \\
December & $31.4 \%$ & 8.0 & 81.9 \\
\hline
\end{tabular}

As with temperature, precipitation may be aggregated by month to account for monthly variation and sub-divided into two distributions: Bernoulli probability of precipitation versus no precipitation, and a Gamma distribution for the quantity of rain, given some rainfall [23]. Given the daily average, $\mu$, and daily variation, $\sigma^{2}$, of rainfall, the gamma parameters, $\alpha$ and $\beta$ may be calculated directly.

$$
\alpha=\frac{\mu^{2}}{\sigma^{2}} \quad \beta=\frac{\mu}{\sigma^{2}}
$$

A scalar constant applied to a Gamma distribution is still Gamma [24]. For an hourly distribution, $\alpha$ would remain the same, but the rate parameter, $\beta$, would be multiplied by 24 . To separate precipitation into rainfall and snow, the current temperature is needed. The correlated pair of high and low temperatures for the study period are used in combination with the mean correction factor.

For example, there is a $9.2 \%$ probability that the average daily temperature in January 2020 will be less than $0^{\circ} \mathrm{C}$ and a $32.6 \%$ probability of no rain. As such, the probability of snow is $6.2 \%$, which corresponds to an average of 1.9 snowy days in January. However, during 8:00 AM, there is a 30.5\% probability temperatures are below $0^{\circ} \mathrm{C}$ in 2020 . Given the same probability of some rain, there is a $20.6 \%$ probability of snow during that hour, which corresponds to 6.4 mornings with some snow.

\section{Modeling Wind Data and Distributions}

A key factor that influences aviation performance is wind, and drones are highly susceptible due to their limited power and weight. The distribution of wind speeds may be modeled using a variety of known probability distributions with the Weibull ranking among the best [25]; however, many models have been shown to be adequate. The creation of wind models is dependent on both the amount of historical data and the temporal granularity. For example, the inclusion of only a daily mean will not be enough to define most parametric models. A generalized understanding of wind effects does not require the accuracy of many climate models. As such, the choice of a probability distribution should be based on what can provide a reasonable approximation based on available data [26].

There are long time series for Portland wind data, including historical average speeds, maximum gusts, percent calm, and direction. Gradient descent optimization was employed to find distribution parameters that provided reasonable approximations of historical trends. In Portland, different times of the year have different distributions of wind, which will directly influence failure odds. The distribution of wind speeds over a year is given in Figure 5. 


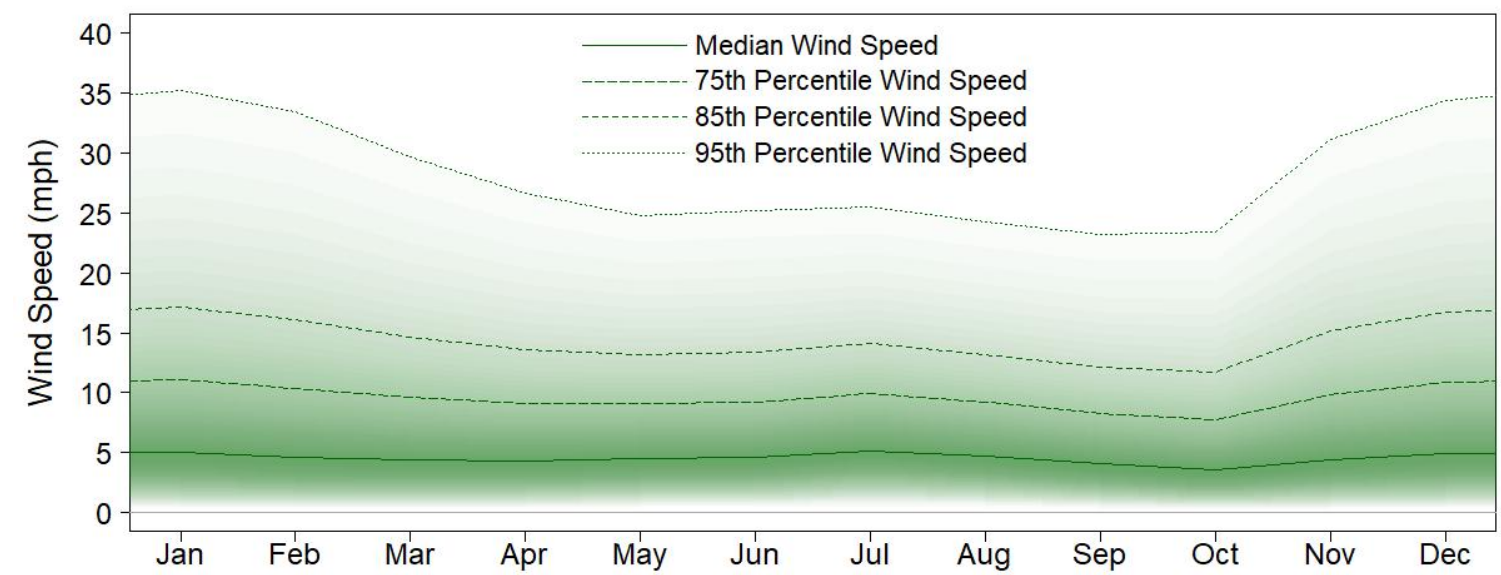

Wind direction is also important. In Portland, winds mostly blow in the ESE direction during the winter months and the NW direction during the summer months (see Figure 6). This factor is important for determining a drone's range at different times of the year. In January, areas to the NW of a depot will be
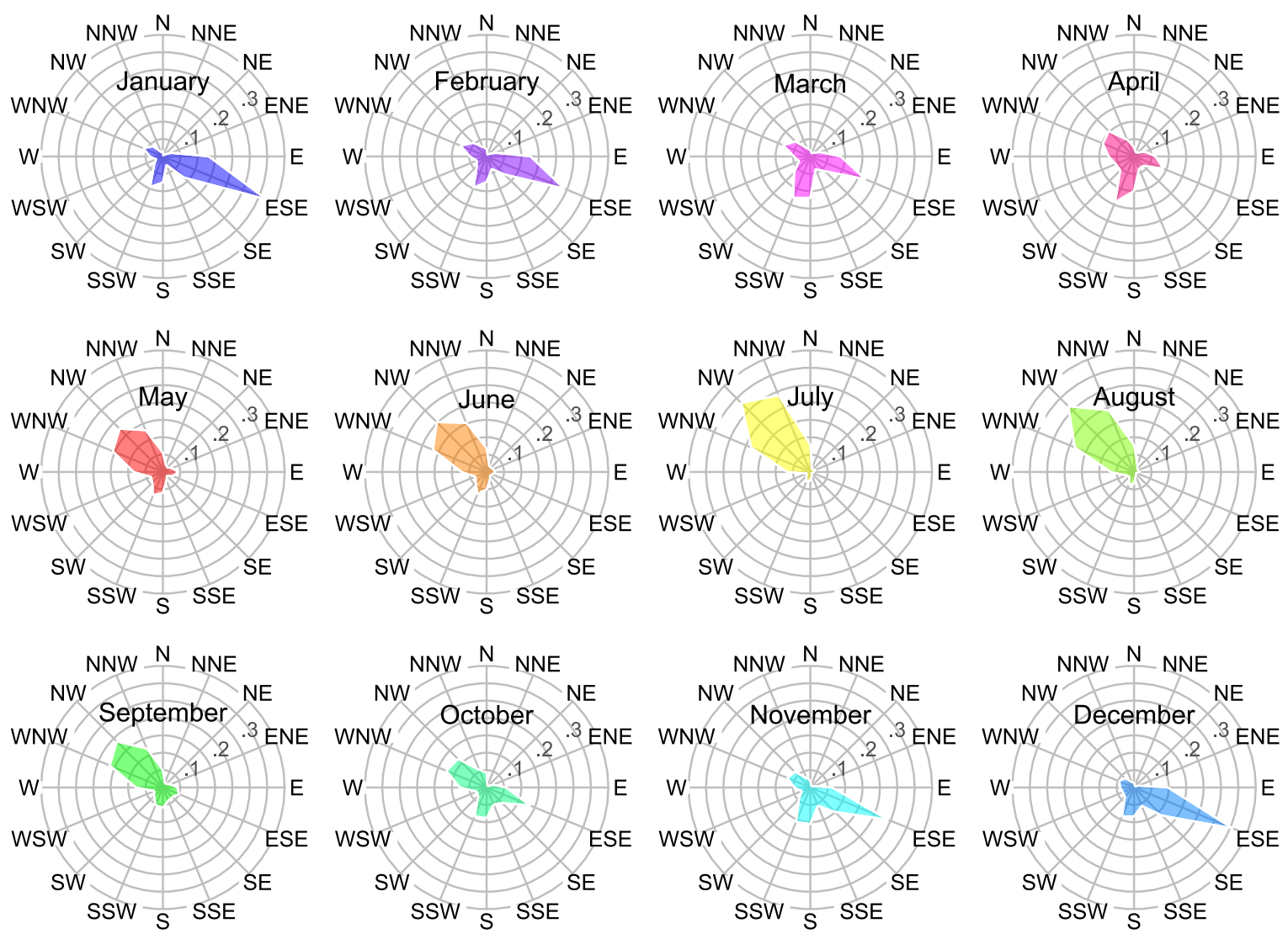

Figure 6 Probability of wind direction for each month in Portland, OR 
1

\section{RANGE RELIABILITY MODELING}

The range of a drone is determined by its weight, flying efficiency, and battery capacity. For applications with a central hub, this range is half of the distance a drone can travel, as a return trip must be accommodated. The following gives the energy necessary for level flight [16]:

where:

$$
p_{l}(t)=\frac{\left(m_{t}+m_{b}+m_{l}\right) g}{\vartheta(s) \eta_{p}} d[\text { unitless }<1]
$$

$$
\begin{aligned}
p_{l} & =\text { power required for level flight [watts], } \\
t & =\text { travel time [seconds] }=(d / s) \\
m_{b} & =\text { drone battery mass }[\mathrm{kg}] \\
m_{l} & =\text { drone load (defibrillator) mass }[\mathrm{kg}] \\
m_{t} & =\text { drone mass tare (i. e. without battery and load) }[\mathrm{kg}] \\
d & =\text { travel distance }[\mathrm{m}] \\
\vartheta(s) & =\text { lift }: \text { to }: \text { drag ratio, or }(L / D)[\text { unitless] } \\
s & =\text { travel speed }[\mathrm{m}], \text { and } \\
\eta_{p} & =\text { total drone power transfer efficiency. }
\end{aligned}
$$

From (1) it is possible to observe that energy consumption is directly proportional to drone mass and travel time and distance. The range estimations of this research consider the defibrillator $1.1 \mathrm{~kg}(2.4$ lb) payload.

\section{Modeling the Impact of Temperature}

Temperature can have a significant impact on drone performance because drone lithium-ion batteries show optimal performance at approximately $20^{\circ} \mathrm{C}\left(68^{\circ} \mathrm{F}\right)$ but perform significantly worse at lower temperatures (see Figure 7). For lithium batteries, the output voltage is dependent on its operating temperature [27]. In this study, battery available energy or capacity is assumed to decrease following a parabolic curve. The maximum $(100 \%)$ will be at $20^{\circ} \mathrm{C}\left(68^{\circ} \mathrm{F}\right)$ and the minimum $(50 \%)$ at $-20^{\circ} \mathrm{C}\left(-4^{\circ} \mathrm{F}\right)$. At higher temperatures, the capacity decreases linearly from $100 \%$ to $95 \%$ from $20^{\circ} \mathrm{C}\left(68^{\circ} \mathrm{F}\right)$ to $55^{\circ} \mathrm{C}\left(131^{\circ} \mathrm{F}\right)$. Battery makers recommend no operation outside this temperature range [18].

$$
\text { capacity }=\left\{\begin{array}{cc}
-0.0003125 t^{2}+0.0125 t+0.875 & -20<t<20 \\
1-.05\left(\frac{t-20}{55-20}\right) & 20 \leq t<55 \\
0 & \text { otherwise }
\end{array}\right.
$$

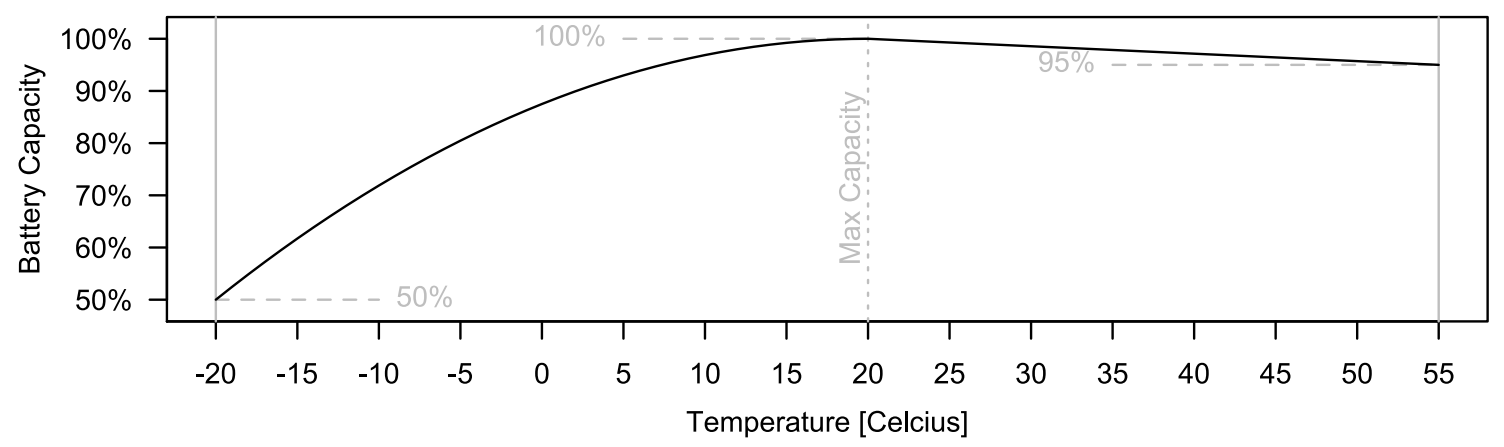

Figure 7 Battery capacity versus temperature and equations 
In addition, battery capacity degrades linearly with the number of cycles up to a point. Often, the degradation accelerates when a battery reaches $80 \%$ of optimal capacity. At this point, the battery is considered unreliable and no longer used. Prior to this point, the battery will have above $80 \%$ optimal capacity, but the exact amount will be unknown for any specific trip. As such, a random uniform distribution from 0.8 to 1.0 may be used in association with temperature for simulation to define the initial condition of the battery with an assumption that faulty or unreliable batteries will not be used.

OHCA events are more frequent during the 8:00 AM hour, which is typically the coldest hour of the day. As such, only the distribution of low temperatures is needed in this study. Figure 8 shows the means and confidence intervals for daily high and low temperatures.

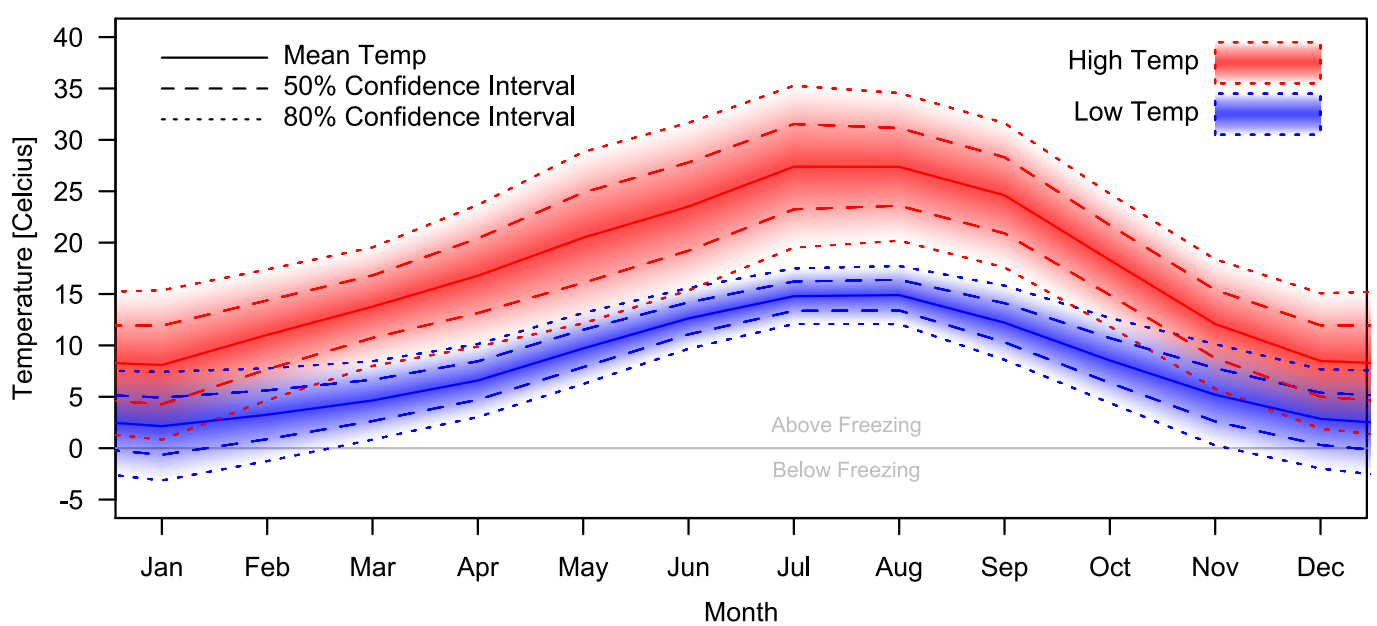

Figure 8 Means and confidence intervals for high and low temperatures by month

15

Figure 9 shows the probability of failure as a function of the total distance traveled, assuming an ideal 42-minute flight time. The left and right edges of the shaded regions are defined using distributions of the low and high temperatures, respectively. The purple area is based on the yearly average highs and lows, while the blue region represents the worst-case (i.e., coldest) temperatures in January. The potential range of a drone will be half of the total available flight distance, as return trips must be accommodated. The probability of failure is the percent of simulated trips that failed to reach a given range.

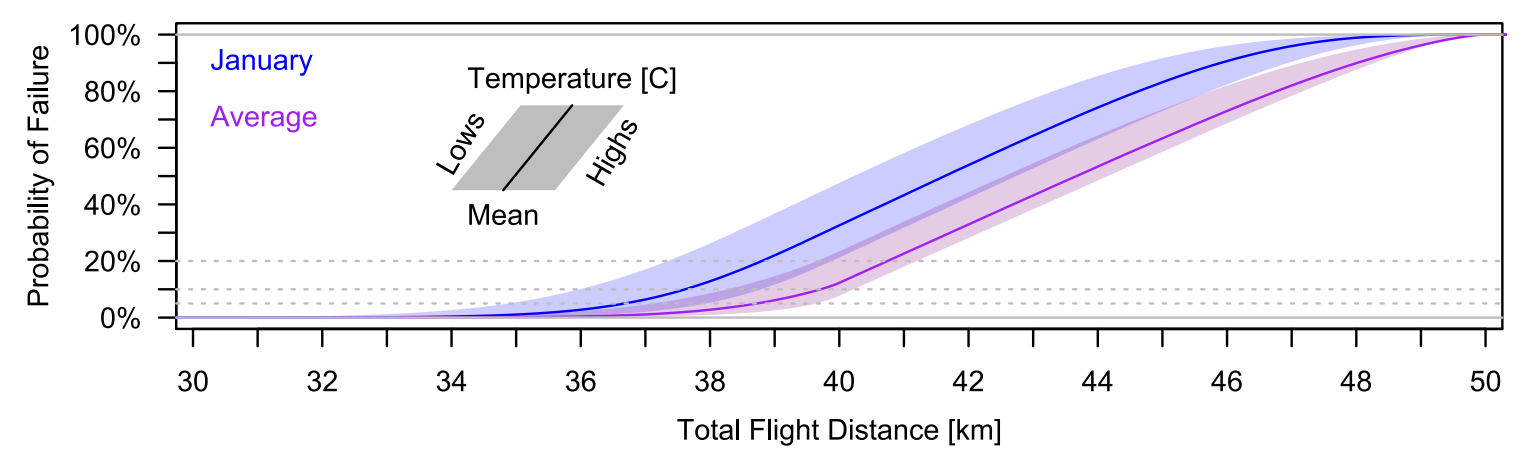

Figure 9 Probability of failure due to temperature and available battery charge versus flight distance

Winter will have worst-case flight ranges as compared to the yearly averages. Yet, the range in the worst case is still larger than the maximum allowable due to time constraints for urgent medical deliveries. 
Even allowing for 14.5 minutes of flight time, the average ambulance arrival time in rural areas, more than $95 \%$ of drones will have enough battery for the $35 \mathrm{~km}(22 \mathrm{mi})$ trip, $17.5 \mathrm{~km}(11 \mathrm{mi})$ in each direction.

In addition, the available range corresponds to a large service area. The 3-minute delivery area covers $40 \mathrm{~km}^{2}\left(15.7 \mathrm{mi}^{2}\right.$ ), while 7 minutes (the urban ambulance average response time) allow for an area of $222 \mathrm{~km}^{2}\left(86 \mathrm{mi}^{2}\right)$. This is functionally the size of many cities. Based on Portland weather conditions, large cities would require just a few drone hubs for full coverage.

\section{Modeling the Impact of Precipitation}

Many modern drones advertise some resistance to rain. As such, not all precipitations events would be considered failures. Considering rain alone (i.e., no snow), defining a specific cutoff for the permitted amount of rain would result in different failure odds. Figure 10 shows probability failure (plotted logarithmically) as a function of the maximum allowable precipitation rate. As an example, if drones are not sent during heavy rain, then drones will be unavailable (a failure condition) $4 \%$ of the time in January and $<0.1 \%$ of the time in July.

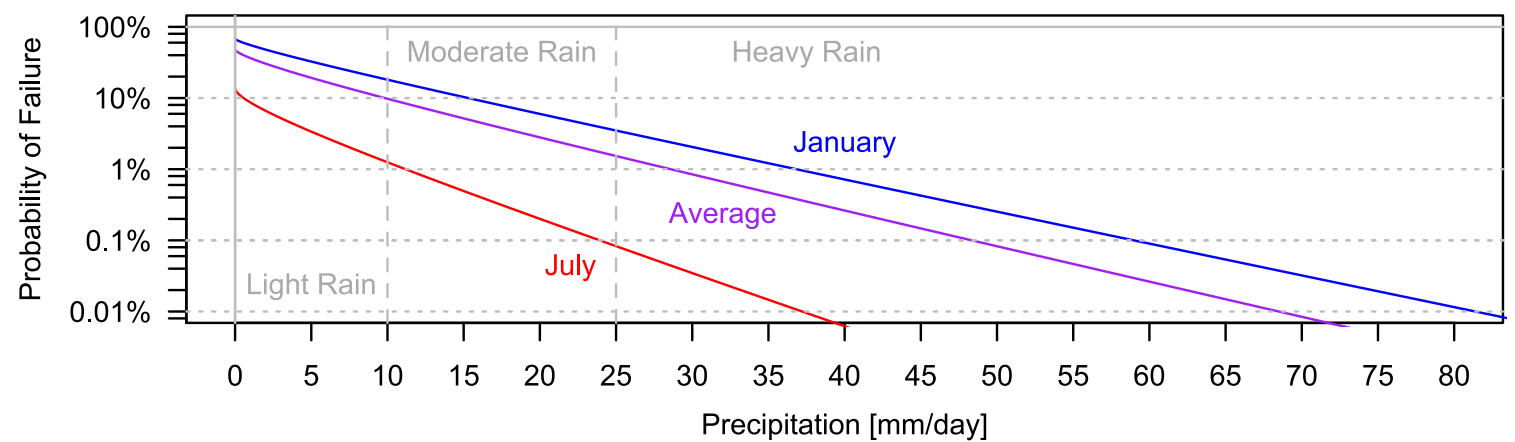

Figure 10 Probability of failure as a function of rainfall rate cutoff

Most drone manufacturers recommend not to fly drones during snowfalls. As such, all snowy weather would cause a failure condition. However, if the amount of snow is considered such that some snowfall is acceptable, the failure rates are also dependent on the precipitation cutoff (see Figure 11).

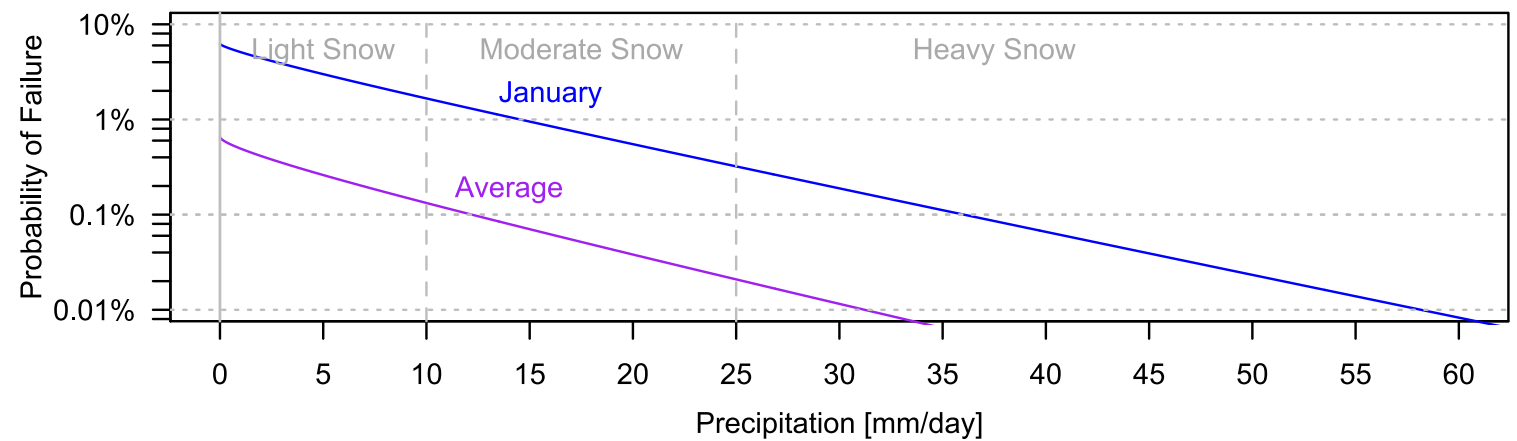

Figure 11 Probability of failure as a function of snowfall rate cutoff.

The cutoff points for snow and rain do not need to be equal. For example, if drones are permitted to fly in snow up to $10 \mathrm{~mm}$ /day (light snow) and rain up to $25 \mathrm{~mm}$ /day (light and moderate rain), then drones in January will be unavailable about $2 \%$ of the time due to snow and about $4 \%$ of the time due to rain. 


\section{Modeling the Impact of Wind}

For winds, the worst case is a headwind where the flight path is directly against the wind's direction of travel. In the best case, the drone has an increased speed due to a tailwind. Given a wind bearing, its speed, and a drone's flight speed, an angle-side-side triangle is formed (Figure 12). This arrangement requires an algorithm to solve as there may be 0,1 , or 2 possible answers. The following algorithm may be used to solve for the fastest feasible flight path, if possible. It combines the law of cosines and solves for the unknown using the quadratic formula. $s_{w}$ is wind speed, $s_{d}$ is drone speed, and $r_{w}$ is the angle between wind bearing and destination bearing.

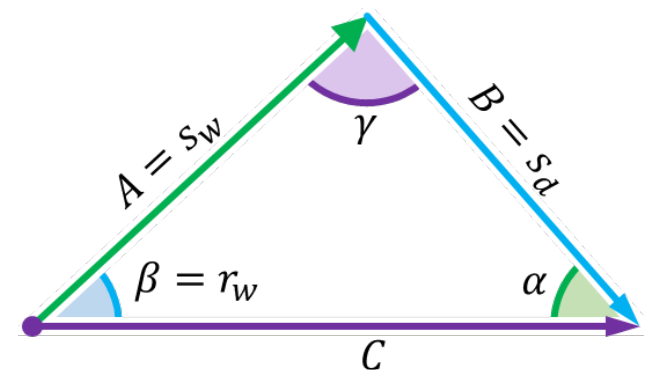

Figure 12 Setup and notation to solve an angle-side-side triangle.

2

4

Solve for 0 , then put in the quadratic form with $C$ as the unknown.

$$
B^{2}=A^{2}+C^{2}-2 A C \cos (\beta)
$$

$$
\begin{aligned}
0 & =A^{2}+C^{2}-2 A C \cos (\beta)-B^{2} \\
& =(1) C^{2}+(-2 A \cos (\beta)) C+\left(A^{2}-B^{2}\right)
\end{aligned}
$$

Solve for $C$ using the quadratic formula and simplify.

$$
\begin{aligned}
C & =\frac{-(-2 A \cos (\beta)) \pm \sqrt{(-2 A \cos (\beta))^{2}-4(1)\left(A^{2}-B^{2}\right)}}{2(1)} \\
& =\frac{2 A \cos (\beta) \pm 2 \sqrt{A^{2} \cos ^{2}(\beta)-\left(A^{2}-B^{2}\right)}}{2} \\
& =A \cos (\beta) \pm \sqrt{B^{2}+A^{2}\left(\cos ^{2}(\beta)-1\right)} \\
& =A \cos (\beta) \pm \sqrt{B^{2}-A^{2} \sin ^{2}(\beta)}
\end{aligned}
$$

Mathematically, there are potentially two solutions, $C_{1}$ and $C_{2}$.

$$
\begin{aligned}
& C_{1}=A \cos (\beta)+\sqrt{B^{2}-A^{2} \sin ^{2}(\beta)} \\
& C_{2}=A \cos (\beta)-\sqrt{B^{2}-A^{2} \sin ^{2}(\beta)}
\end{aligned}
$$

However, in the context of flight speed triangles, negative and imaginary solutions are not applicable, and the fastest speed is preferred. Given that $C_{1} \geq C_{2}$ for real solutions, $C_{1}$ is used, given that the quantity under the square root is greater than 0 .

As an example, assume a drone speed of $20 \mathrm{mps}$, wind speed of $30 \mathrm{mps}$, and a wind direction $30^{\circ}$ away from the travel direction, both triangles in Figure 13 are valid solutions where the drone flies at a $20 \mathrm{mps}$ and is able to reach the destination. The key factor is the effective travel speeds and initial flight bearings. A drone using the initial travel bearing from the second triangle would reach its destination three times faster than a drone using the initial bearing from the first. 


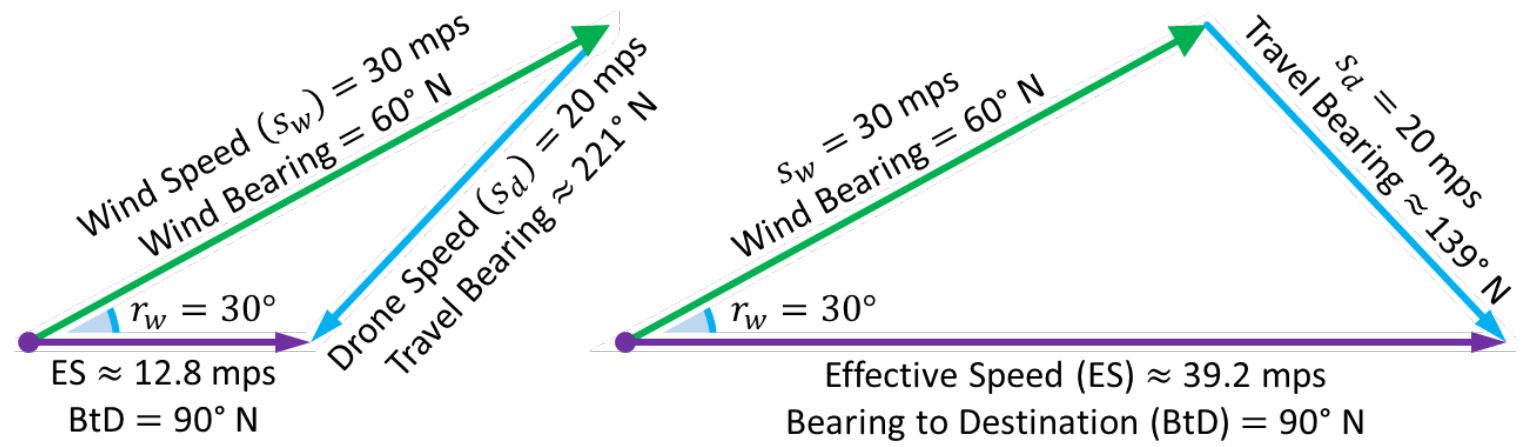

Figure 13 Two valid solutions to an angle-side-side triangle problem

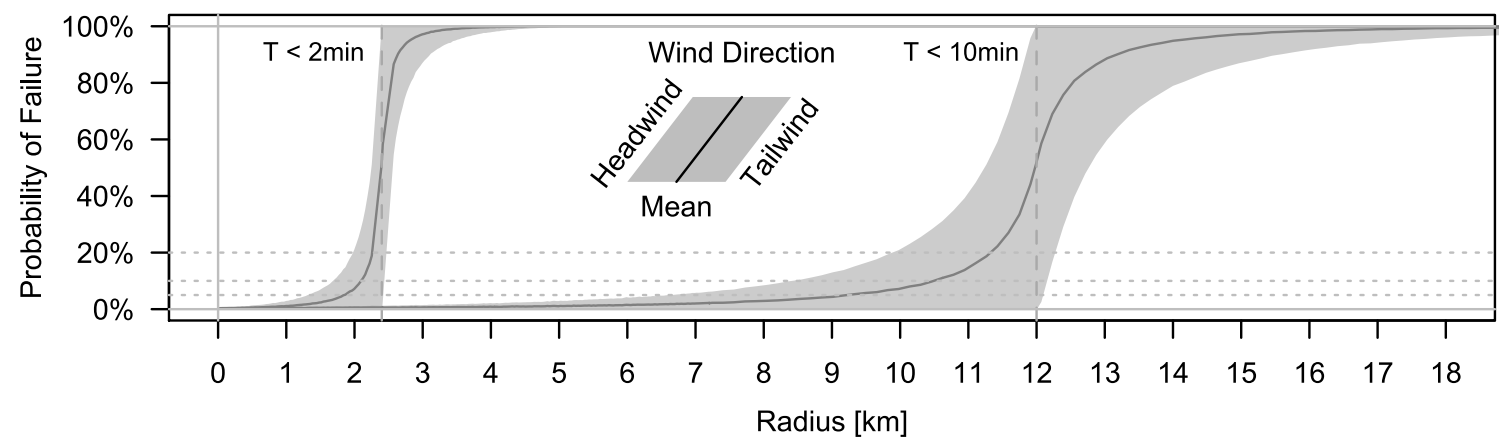

Figure 14 Probability of failure versus radius due to wind with linear $y$-axis

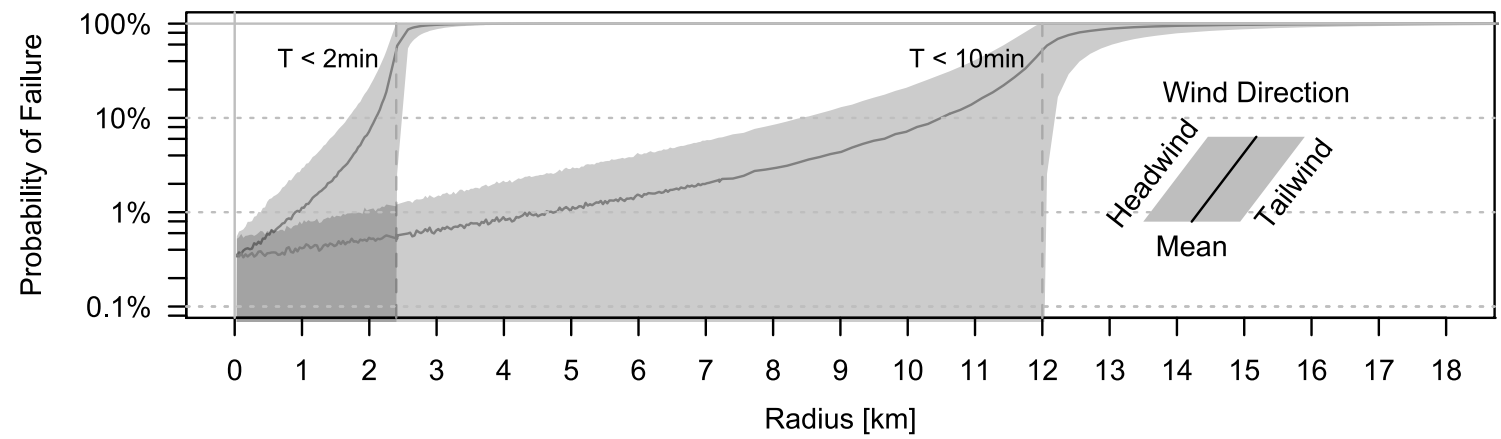


Figure 15 shows that the average potential failure from wind is above $0.1 \%$ for a 2 minute or a 10 minute trip. Wind plays a key role in determining acceptable failure rates and for determining a potential range for drone deliveries. Notably, having multiple hubs will reduce failure rates from the wind as different hubs may be employed depending on wind direction. Headwinds and potential failure from one direction may be tailwinds and success from another.

\section{CONCLUSIONS}

For the delivery of time-sensitive supplies, drones may provide the means to bypass many obstacles experienced by ground transportation. However, drones are subject to their own set of constraints that limit the likelihood of successful deliveries. While packages from an online retailer can be delayed by hours without substantial ill effect, even short delays, in the context of medical supplies, can be fatal. This research utilized real-world data to examine the impact of stochastic demand and weather conditions on drone delivery reliability.

The number of drones needed is highly dependent on charge times, use of battery swapping, and population in the service area. The specific application of drones to deliver defibrillators must consider that the average OHCA demand rate increases 2.91 times Monday morning. This worst-case scenario and economic considerations should be used to define the required equipment for a service area. Additional consideration should also be given to potential mechanical failures and maintenance schedules. Given the equipment costs, one potential solution is a requirement for one extra drone over the calculated minimum, extra batteries, and equipment to check battery health. Lastly, it is important to note that failure due to extreme weather conditions cannot be addressed by simply having more available drones. Extreme weather conditions, which will result in a failed delivery for one drone, will result in a failed delivery for any other drone because drones cannot operate under extreme weather conditions. Summarizing, proper fleet sizing can address variability in demand as well as variability in weather conditions but will not eliminate delivery failures due to extreme weather conditions when drones cannot operate.

In this case study, the wind is a key factor; even the average winds of Portland in January will cause failures, defined by travel time constraints, more than $1 \%$ of the time. The direction of winds also changes depending on the time of year. The placement of drone hubs should consider ranges defined both by temporal constraints given by OHCA events survival rates as well as probabilistic failure odds caused by winds. Studies that examine multiple hubs could also consider potential failure rates and repositioning strategies considering the seasonality of weather conditions.

The temperature in Portland is not as crucial as wind to have reliable drone deliveries. The large potential delivery range of high-quality drones combined with strict delivery time limits reduces the negative effects of temperature and charge cycles. Hence, temperature, as it relates to battery function, may be ignored for these types of deliveries since the potential for failure remains low. For example, a $14 \mathrm{~km}$ (8.7 mi) trip ( $28 \mathrm{~km}$ or $17.4 \mathrm{mi}$ both ways) would have less than $0.001 \%$ failure odds due to temperature and charge decay in the worst case. While extreme temperatures have limited negative effects on batteries, wildfires, a cause of such extreme conditions, may potentially limit drone operations due to difficult operating conditions and "no-fly orders" issued by federal, state, and local wildland fire management agencies and the FAA [28]. Wildfires are an important issue, but outside of the scope of this paper due to the lack of detailed historical data required to model and predict wildfire intensity, winds, location, etc. These issues are compounded by a dynamic problem due to greenhouse gas emissions and their effect on wildfire characteristics and seasonality.

Precipitation failures are highly dependent on the level of precipitation considered too high to send a drone. The rate of failures, defined by the probability of not sending a drone, changes throughout the year and by the time of day. If a drone is rated for higher water resistance, the failure rate will be lower. Furthermore, temperature also is important as it relates to precipitation, as snow has larger adverse effects on drone operations as compared to rain.

This paper examined several of the mechanical and meteorological impacts on drone deliveries to examine which factors are most important and to define limits. Results indicate that successful drone deliveries of AEDs are highly influenced by wind speeds, wind direction, and precipitation rates; however, 
the ambient temperature may mostly be ignored for short and strict delivery times limits. Additionally, battery swapping may be highly effective at reducing equipment requirements given worst-case demand.

Given adequate historical data about weather and demand, drone delivery operators should be able to plan efficiently to meet peak demand periods without unacceptable failure rates or excessive costs. Winds will remain an obstacle in some parts of the year unless drone speeds can be improved. While drones may provide fast delivery times for the vast majority of cases, some failures will be difficult to avoid. Ideally, service areas should remain small enough that travel times are not limited by distance, and overlap of service hubs will provide alternative delivery routes when wind direction is not ideal.

Future research could also examine the likelihood that the delivery of automatic defibrillators will be able to be operated, given that only one-third of OHCA are witnessed by another person. This paper assumes $100 \%$ reporting for OHCA events; as such, the rate, $\mu_{n}$, represents a highest-demand condition, and the time between events will likely be longer than estimated, as not all will be reported. In the event that someone is able to call emergency services, drone deliveries may be valid but cannot be employed when another person is not present for operations.

Furthermore, there is an access and equity question associated with a drone's ability to deliver to some areas. For example, airports are often restricted flight zones that allow for no drone operations. Such areas are also areas with higher proportions of lower-income communities. Future research could examine where a delivery system could be employed and what ground delivery systems are required locally to adjust for access differences. In addition, future research efforts should analyze how COVID-19 and subsequent lockdowns have greatly increased opportunities to deploy fleets of drones for time-sensitive deliveries. 


\section{AUTHOR CONTRIBUTIONS}

The authors confirm contribution to the paper as follows: Study conception and design: MF, TG; Data collection: TG, MF; Analysis and interpretation of results: TG, MF, AU; Draft manuscript preparation: TG, MF, AU. All authors reviewed the results and approved the final version of the manuscript.

\section{ACKNOWLEDGEMENTS}

This research was funded by the Freight Mobility Research Institute (FMRI), a U.S. DOT University Transportation Center.

\section{REFERENCES}

[1] Ministry of Infrastructure, "Public Transport Policy and Strategy for Rwanda," Kigali, 2012.

[2] J. Chen, "Rwanda has shown that healthcare innovation in the developing world means more than investing in technology," Thomas Reuters Foundation News, 22 August 2017. [Online]. Available: https://news.trust.org/item/20170821144058-29rg6/. [Accessed 2019].

[3] S. Denby, "The Super-Fast Logistics of Delivering Blood By Drone," Wendover Productions, 2019. [Online]. Available: https://www.youtube.com/watch?v=bnoUBfLxZz0. [Accessed 2019].

[4] J.R. Scalea, S. Restaino, M. Scassero, G. Blankenship, S. Bartlett and N. Wereley, "An Initial Investigation of Unmanned Aircraft Systems (UAS) and Real-Time Organ Status measurement for Transporting Human Organs," IEEE Journal of Translational Engineering in Health and Medicine, vol. 6, pp. 1-7, 2018.

[5] S.C. Brooks, R.H. Schmicker, T.D. Rea, T.P. Aufderheide, D.P. Davis, L.J. Morrison, R. Sahni, G.K. Sears, D.E. Griffiths, G. Sopko, S.S. Emerson, P. Dorian and ROC Investigators, "Out-of-Hospital Cardiac Arrest Frequency and Survival: Evidence for Temporal Variability," Resuscitation: Official Journal of the European Resuscitation Council, vol. 81, no. 2, pp. 175-181, 2010.

[6] American Heart Association, "Heart Disease and Stroke Statistics - 2018 Update: A Report From the American Heart Association," Circulation, vol. 137, no. 12, 2018.

[7] "HeartSine Samaritan PAD 450P AED," Foremost, 2019. [Online]. Available: https://www.foremostequipment.com/heartsine-samaritan-pad-450p-aed-new/. [Accessed 2019].

[8] P.S. Chan, H.M. Krumholz, G. Nichol and B.K. Nallamothu, "Delayed Time to Defibrillation after In-Hospital Cardiac Arrest," The New England Journal of Medicine, vol. 358, no. 1, pp. 9-17, 2008.

[9] H.K. Mell, S.N. Mumma, B. Heistand, B.G. Carr, T. Holland and J. Stopyra, "Emergency Medical Services Response Times in Rural, Suburban, and Urban Areas," JAMA surgery, vol. 152, no. 10, pp. 983-984, 2017.

[10] M. Glover and T. Colton, "Workhorse Partners with USOG to Launch Pilot Programs for Drone Delivery of Medical Supplies," BioSpace, 08 October 2019. [Online]. Available: https://www.biospace.com/article/releases/workhorse-partners-with-usog-to-launch-pilot-programsfor-drone-delivery-of-medical-supplies/. [Accessed 2019].

[11] A. Claesson, A. Bäckman, M. Ringh, L. Svensson, P. Nordberg, T. Djärv and J. Hollenberg, "Time to Delivery of an Automated External Defibrillator Using a Drone for Simulated Out-of-Hospital Cardiac Arrests vs Emergency Medical Services," JAMA, vol. 317, no. 22, pp. 2332-2334, 2017.

[12] A. Pulver and R. Wei, "Optimizing the Spatial Location of Medical Drones," Applied Geography, vol. 90, pp. 9-16, 2018.

[13] J.J. Boutilier, S.C. Brooks, A. Janmohamed, A. Byers, J.E. Buick, C. Zhan, A.P. Schoellig, S. Cheskes, L.J. Morrison and T.C.Y. Chan, "Optimizing a Drone Network to Deliver Automated External Defribrillators," Applied Geography, vol. 135, no. 25, pp. 2454-2465, 2017.

[14] G. Casella and R.L. Berger, Statistical Inference, 2nd ed., Pacific Grove, CA: Daxbury, 2002. 
[15] A.M. Nordenskjöld, K.M. Eggers, T. Jernberg, M.A. Mohammad, D. Erlinge and B. Lindahl, "Circadian onset and prognosis of myocardial infarction with non-obstructive coronary arteries (MINOCA)," PLOS ONE, vol. 4, p. 14, 2019.

[16] M.A. Figliozzi, "Lifecycle modeling and assessment of unmanned aerial vehicles (Drones) CO2e emissions.," Transportation Research Part D, vol. 57, pp. 251-261, 2017.

[17] microdrones, "The Heavy-Lifting Drone md4-3000," 2019. [Online]. Available: https://www.microdrones.com/en/drones/md4-3000/. [Accessed 2019].

[18] Alibaba, "36v 10ah lipo battery," 2019. [Online]. Available: https://www.alibaba.com/productdetail/36v-10ah-lipo-battery-for-e_60444386060.html. [Accessed 2019].

[19] Aniwaa, "MD4-3000 Microdrones," Aniwaa Pte Ltd, 2019. [Online]. Available: https://www.aniwaa.com/product/drones/microdrones-md4-3000/. [Accessed 2019].

[20] J. Rickert, "Simulating from the Bivariate Normal Distribution in R," 04 August 2016. [Online]. Available: https://blog.revolutionanalytics.com/2016/08/simulating-form-the-bivariate-normaldistribution-in-r-1.html. [Accessed 2019].

[21] "Normal distribution," 2019. [Online]. Available: https://en.wikipedia.org/wiki/Normal_distribution. [Accessed 2019].

[22] "Sum of normally distributed random variables," 2019. [Online]. Available: https://en.wikipedia.org/wiki/Sum_of_normally_distributed_random_variables. [Accessed 2019].

[23] Z. Li, F. Brissette and J. Chen, "Finding the most appropriate precipitation probability distribution for stochastic weather generation and hydrological modelling in Nordic watersheds," Hydrological Processes, vol. 27, pp. 3718-3729, 2013.

[24] "Gamma distribution," 2019. [Online]. Available: https://en.wikipedia.org/wiki/Gamma_distribution. [Accessed 2019].

[25] Z. Qin, W. Li and X. Xionga, "Estimating wind speed probability distribution using kernel density method," Electric Power Systems Research, vol. 81, no. 12, pp. 2139-2146, 2011.

[26] NOAA, "Climate Data Online," 2019. [Online]. Available: https://www.ncdc.noaa.gov/cdo-web/. [Accessed 2017].

[27] E. Samadani, "Modeling of Lithium-ion Battery Performance and Thermal Behavior in Electrified Vehicles," University of Waterloo, Waterloo, Ontario, Canada, 2015.

[28] U.S. Forest Service, "If You Fly, We Can't," United States Department of Agriculture, 2019. [Online]. Available: https://www.fs.usda.gov/managing-land/fire/uas/if-you-fly. [Accessed 2020]. 